\section{SIFAT MACHIAVELLIAN, ORIENTASI ETIS, EQUITY SENSITIIVITY DAN \\ BUDAYA JAWA TERHADAP PERILAKU ETIS DENGAN INDEPENDENSI SEBAGAI VARIABEL INTERVENING}

\author{
Titis Puspitaningrum Dewi Kartika \\ STIE Perbanas Surabaya \\ Jl. Nginden Semolo No. 34-36, Jangkungan, Sukolilo, Surabaya \\ Titis_puspita@perbanas.ac.id
}

\begin{abstract}
This study would like to examine the influences on Machiavellian characteristic, Equity Sensitivity, and Javanese Culture to Ethical Behavior as the intervening variable. Sample used in this study was auditor at KAP in Surabaya. This study also used path analysis for technique data analysis. The result of reliable and validity test showed that the questionnaire is reliable, while the validity demonstrated that from 91 total question items, 28 items are not valid. The result of this study indicated that auditor with high Machiavellian character will tend to behave independently is unproven. However, it is proven that auditors with high Machiavellian character will tend to behave unethically. Auditor with Machiavellian character who has an effect on ethical behavior followed by independent attitude as intervening variable is unproven. The hypothesis that auditor with high level of independency will tend to influence ethical behavior is unproven. Ethical orientation influenced on ethical behavior is unproven. It is proven that Equity Sensitivity influenced on ethical behavior. In addition, the hypothesis that Javanese Culture has an effect on ethical behavior is proven. Consequently, independency could not be proven as intervening variable which influences between Machiavellian character to Ethical Behavior.
\end{abstract}

Keywords: Ethical Orientation, Equity Sensitivity, Javanese Culture, Ethical Behavior, Independency, Machiavellian

\section{PENDAHULUAN}

Etika profesi mengatur bagaimana seharusnya kesadaran etika dan sikapsikap auditor dalam menjalankan tugasnya. Kesadaran etika dan sikap professional yang merupakan kepribadiannnya harus ada dalam diri auditor mengingat bahwa profesi tersebut sangat membutuhkan kepercayaan masyarakat terhadap kualitas audit yang diberikan. Richmond (2003) dalam Purnamasari (2006) menemukan bukti bahwa kepribadian individu mempengaruhi perilaku etis, dengan menginvestigasikan hubungan paham Machiavellian yang membentuk suatu tipe kepribadian yang dibenut sifat Machiavellian serta pertimbangan etis dengan kecenderungan perilaku individu dalam meghadapi dilemma-dilema etika (perilaku etis). Hasil penelitian tersebut menunjukkan bahwa semakin tinggi kecenderungan sifat Machiavellian seseorang maka semakin mungkin untuk berperilaku tidak etis. Dan semakin tinggi level pertimbangan etis seseorang maka seseorang tersebut akan semakin perperilaku etis.

Berbagai kasus pelanggaran etika seharusnya tidak terjadi apabila auditor mempunyai pengetahuan, pemahaman, dan kemauan untuk menerapkan nilainilai moral dan etika secara memadai dalam pelaksanaan pekerjaan profesionalnya. Issue mengenai etika auditor sangat menarik sejak munculnya kasus Enron yang melibatkan salah satu Kantor Akuntan Publik (KAP) The Big Five Artur Andersen, selain itu juga ada kasus Xerox dan Walt Disney. Di Indonesia terdapat kasus 
Sifat

Machiavellian,

Orientasi

Etis...

1024
PT.Telkom yang meilbatkan KAP Eddy Pianto \& Rekan dan KAP Drs. Hadi Susanto \& Rekan. Dimana laporan keuangan PT. Telkom tidak diakui oleh SEC (pemegang otoritas pasar modal di Amerika Serikat). Kemudian juga kasus KPMG-Siddharta \& Harsono yan terbukti menyogok aparat pajak di Indonesia dengan menerbitkan faktur palsu untuk biaya jasa profesioal KPMG yang harus dibayar kliennya PT. Easman Christensen (Ludigdo, 2007:11). Kasus pelanggaran etika yang telah menimpa KAP berdampak negative pada tingkat kepercayaan public dan persepsi terhadap profesi akuntan. Zpemberitaan yang terjadi tentang froud pada dunia akuntansi menimbulkan perhatian public dalam penilaian etika dan perilaku auditor.

Sikap independen pada auditor juga memiliki peran dalam pengelolaan sebuah resiko yang pada akhirnya akan membentuk sebuah laporan audit dan tentunya berlandaskan pada kode etik profesi. Penilaian dari risiko dan independensi auditor menggambarkan tentang seberapa besar pencegahan tindak kriminalitas penyalahgunaan dana perusahaan atau organisasi terhadap suatu entitas audit yang dapat diminimalisasi, sehingga factor-faktor kemungkinan terjadinya penyalahgunaan laporan keuangan tidak akan terjadi.

Penelitian mengenai factor-faktor yang memperngaruhi sikap dan perilaku etis seseorang salah satunya adalah Equity Sensitivity atau prinsip keadilan. Penelitian Mueller dan Clarke (1998) dalam Lucyanda dan Endro (2012) menunjukkan bahwa perilaku seseorang dipengaruhi oleh persepsi mereka terhadap Equity Sensitivity. Dimana Equity Sensitivity didefinisikan sebagai variable personalitas yang menunjukkan reaksi individu ketika merasakan adil atau tidak adil. Casson (1993) dalam Ajdi (2012) menyebutkan bahwa bila dikaitkan dengan keadilan, ternyata aspek moral dan budaya yang lebih banyak berperan. Dimana kemampuan seorang professional dalam memahami persoalan etika juga sangat dipengaruhi oleh lingkkungan dimana dia berada. Seperti yang diungkapkan oleh Audry (2010) bahwa budaya mempengaruhi perilaku yang dibawanya atau sikap seseorang melalui nilai-nilai yang dibawanya melalui lingkungan sekitarnya.

Berdasarkan hal-hal tersebut muncul alasan mengapa penelitian ini penting dilakukan, pertama, mengenai fenimena perilaku tidak etis auditor. Kedua, penelitian ini ingin melihat sifat Machiavellian auditor di Surabaya. Dimana Machiavellian itu sendiri sifat yang memiliki kecenderungan untuk memanipulasi orang lain. Beberapa hasil penelitian menunjukkan bahwa semakin tinggi kecenderungan sifat Machiavellian seseorang maka semakin mungkin untuk berperilaku tidak etis. Dan semakin tinggi level pertimbangan etis seseorang maka seseorang tersebut akan semakin perperilaku etis Purnamasari (2006). Ketiga, penelitian ini berfokus pada independensi, orientasi etis yang mempengaruhi perilaku etis auditor. Keempat, salah satu faktor yang mempengaruhi sikap dan perilaku etis seseorang adalah prinsip keadilan (Equity Sensitivity) yang berpengaruh pada tindakan etis seseorang dalam pengambilan keputusan. Kelima, berkaitan dengan budaya jawa dimana perseberannya sangat homogenitas yang mempengaruhi pandangan hidup sebagian besar masayrakat Indonesia.

\section{Rumusan Masalah}

1. Apakah auditor dengan sifat Machiavellian tinggi akan cenderung berperilaku tidak etis?

2. Apakah auditor dengan level independensi yang tinggi akan semakin berperilaku etis?

3. Apakah auditor dengan sifat Machiavellian tinggi akan cenderung berperilaku tidak independen?

4. Apakah orientasi etis berpengaruh terhadap perilaku etis?

5. Apakah Equity Sensitivity berpengaruh terhadap perilaku etis?

6. Apakah factor budaya jawa berpengaruh terhadap perilaku etis? 
Menurut porspektif pengembangan moral kognitif, kapasitas moral individu menjadi lebih sophisticated dan komplek jika individu tersebut mendapatkan tambahan struktur moral kognitif pada setiap peningkatan level pertumbuhan perkembangan moral. Pertumbuhan eksternal berasal dari reward dan punishment yang diberikan, sedangkan pertu mbuhan internal mengarah pada principle dan universal fairness (Kohlberg, 1981) dalam Purnamasari 2006.

\section{KERANGKA PEMIKIRAN}

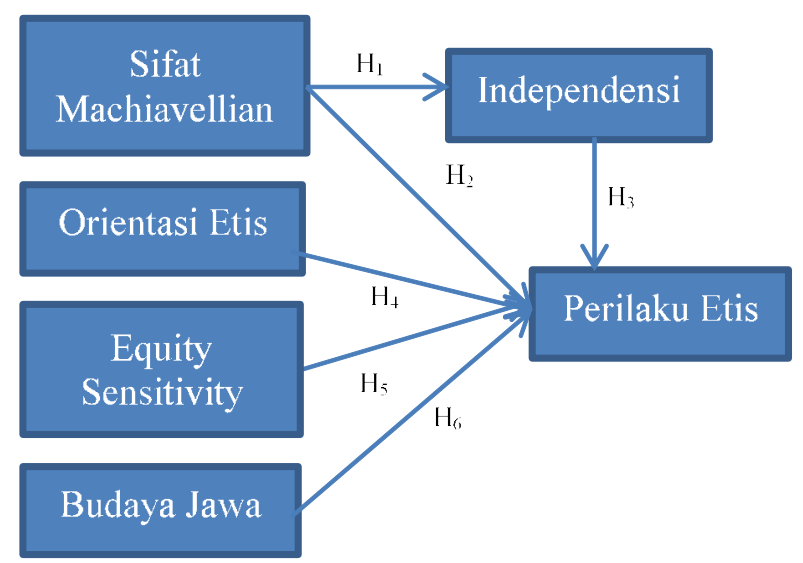

\section{Hipotesis Penelitian}

1. Sifat Machiavellian terhadap Independensi

Christie dan Geis (1970) dalam Purnamasari (2006) mengemukakan bahwa individu dengan sifat Machiavellian tinggi cenderung memanfaatkan situasi untuk mendapatkan keuntungan pribadi. Goch dan Crian (1996) menemukan indikasi bahwa idividu dengan sifat Machiavellian tinggi akan lebih mudah untuk tidak menerima nilai-nilai dalam profesi akuntan yaitu independensi.

$\mathrm{H}_{1}$ : Auditor dengan sifat Machiavellian tinggi akan cenderung berperilaku tidak independen

\section{Sifat Machiavellian terhadap perilaku etis}

Skla Machiavellian ini menjadi proksi perilaku moral yang mempengaruhi perilaku pembuatan keputusan etis (Hegarty dan Sims 1978 dan Trevino et all 1985) dalam Purnamasari 2006. Sehingga dapat diindikasikan bahwa individu dengan sifat Machhiavellian tinggi akan lebih mungkin melakukan tindakan tidak etis dibandingkan individu degan sifat Machiavellian rendah. Richmon (2003) juga menemukan bahwa individu dengan sifat Machiavellian tinggi akan lebih mungkin melakukan tindakan yang tidak etis dibandingankan dengan individu dengan sifat Machiavellian rendah.

$\mathrm{H}_{2 \mathrm{a}}$ : Auditor dengan sifat Machiavellian tinggi akan cenderung berperilaku tidak etis

$\mathrm{H}_{2 b}$ : Auditor dengan sifat Machiavellian memiliki pengaruh terhadap perilaku etis dengan sikap independensi sebagai variable intervening

3. Independensi terhadap Perilaku Etis

Panemon (1992) dalam Purnamasari (2006) menyatakan bahwa level pertimbangan etis yang lebih tinggi akan meningkatkan sensitifitas seorang individu untuk lebih mengkritisi kejadian, masalah dan konflik. Auditor dengan kapasitas pemikiran etis yang tinggi akan lebih baik dalam menghadapi konflik dan dilemma etis. Sweeney dan Roberta (1997) dalam Purnamasari (2006) 


\section{Sifat \\ Machiavellian, Orientasi \\ Etis...}

1026 mengindikasikan bahwa pertimbangan etis berdampak pada independensi auditor. Sehingga semakin tingginya level independensi akan cenderung mempengaruhi [erilaku etis yang dimiliki oleh seoarang auditor.

$\mathrm{H}_{3}$ : Auditor dengan level independensi yang tinggi akan cenderung berpengaruh perilaku etis

4. Orientasi Etis terhadap Perilaku Etis

Orientasi etis seorang auditor merupakan dasar pemikiran auditor untuk menentukan sikap,arah dan sebagainya secara tepat dan benar yang berkaitan dengan dilemma etis. Pengaruh orientasi etis terhadap perilaku auditor dapat dilihat saat seorang auditor memiliki dasar pemikiran untuk menentukan sikap apakah sudah baik. Auditor yang memiliki sikap idealis dalam memutuskan tindakannya akan cenderung mengarah pada pedoman atau aturan yang telah ditetapkan sebelumnya sehingga auditor akan cenderung berperilaku etis. Sama halnya dengan auditor yang memiliki sikap relativisme akan cenderung menolak aturan moral dan merasa bahwa tindakan moral tergantung pada individu dan situasi. Jika sikap ini diterapkan secara tidak tepat maka dapat membuat seseorang berperilaku tidak etis. Hal ini juga diungkapkan oleh Audry (2010) yang menyatakan bahwa seseorang dengan tingkat idealism yang tinggi akan menemukan adanya masalah etika dalam memutuskan suatu tindakan lebih mengarah pada pedoman atau aturan yang telah ditetapkan sehingga lebih berperilaku etis. Sehingga orientasi etis baik idealism maupun relativisme memiliki pengaruh terhadap perilaku etis auditor.

$\mathrm{H}^{4}$ : Orientasi etis berpengaruh terhadap perilaku etis

\section{Equity Sensitivity terhadap Perilaku Etis}

Equity merupakan suatu hal yang berhubungan dengan fairness (keadilan) yang dirasakan seseorang disbanding orang lain. Husemen (1987) menyebutkan tiga tipe individual yang memiliki Equity Sensitivity yaitu benelovent, equity sensitivities, dan entitled. Individu dengan karakter benelovent cenderung berperilaku murah hati dan lebih senanng memberi daripada menerima dan cenderung melakukan tindakan etis sebagai akibat sifatnya yang tidak mementingkan dirinya sendiri. Individu dengan karakter equity sensitivities digambarkan sebagai individu yang memiliki keseimbangan antara inputs dan outcomes. Sedangkan individu dengan karakter entitled digambarkan sebagai individu yang lebih senang menerima daripada memberi dan lebih banyak menuntut haknya daripada memikirkan apa yang dapat diberikan. Kondisi tersebut tidak terlepas dari profesi atau pekerjaan seseorang terutama auditor yang sering dihadapkan pada dilemma etis. Putri (2005) menemukan bahwaa terdapat perbedaan perilaku etis antara auditor benevolents dan auditor entitleds. Dimana auditor benevolents cenderung memiliki perilaku etis. Sehingga dapat diindikasikan bahwa Equity Sensitivity berpengaruh terhadap perilaku etis.

$\mathrm{H}_{5}$ : Equity Sensitivity berpengaruh terhadap perilaku etis

6. Budaya Jawa terhadap Perilaku Etis

Budaya Jawa meliputi cara hidup yang rukun dalam bermasyarakat, namun bukan berarti orang jawa tidak memiliki kepentingan pribadi sama sekali. Individu lebih memilih sikap mencari aman dan mendukung orang lain. Hal ini bisa diindikasikan bahwa auditor yang berasal dari jawa menerapkan prinsip-prinsip budaya Jawa. Hal ini juga mendukung temuan Audry (2010) yang menemukan bahwa budaya jawa berpengaruh positif terhadap perilaku etis auditor yang diterima. Auditor yang berasal dari Jawa yang memegang teguh prinsip-prinsip dalam budaya Jawa akan cenderung mengembangkan perilaku etis. Sehingga dapat disimpulkan bahwa Budaya Jawa memiliki pengaruh terhadap perilaku etis auditor.

$\mathrm{H}_{6}$ : Budaya jawa berpengaruh terhadap perilaku etis 
Populasi dalam penelitian ini adalah auditor seluruh Kantor Akuntan Publi (KAP) yang ada di Surabaya. Seluruh populasi tersebut dijadikan sampel dalam penelitian ini. Tehnik pengambilan sampel berdasarkan convenion sampling.

\section{Definisi Operasional}

1. Variabel Dependen

Variabel dependen dalam penelitian ini adalah Perilaku Etis Auditor (Y). Perilaku etis merupakan perilaku yang dilakukan sesuai dengan norma-norma social yang diterima secara umum oleh masyarakat sehubungan dengan tindakan-tindakan yang benar dan baik. Perilaku etis dapat menentukan kualitas individu yang dipengaruh oleh beberapa faktor. Aturan IAI-KASP memuat prinsip-prinsip dasar perilaku etis auditor yaitu integritas, objektivitas, kompetensi dan kehati-hatian, kerahasiaan, ketepatan bertindak dan standar teknis dan professional. Pengukuran variable perilaku etis auditor menggunakan skala likert $1 \mathrm{sd} 4$. Penelitian ini memfokuskan perilaku etis pada factor-faktor atau substansi kode etik akuntan yang dikembangkan oleh Sihwahjoeni dan Gundono (2000) dengan indikator pelaksanaan kode etik dan penafsiran dan penyempurnaan kode etik. Peneliti mengasumsikan jika responden berpersepsi positif maka auditor cenderung memiliki perilaku lebih etis.

2. Variabel Independen

a. Sifat Machiavellian $\left(\mathrm{X}_{1}\right)$

Kepribadian Machiavelillan dideskripsikan oleh Christen dan Geis (1980) dalam Richmond (2001) sebagai kepribadian yang kurang mempunyai afeksi dalam hubungann personal, mengabikan moralitas konvensional, dan memperlihatkan komitmen ideology yang rendah. Tingkat kecenderungan sifat Machiavellian diukur dengan skala Mach IV yang terdiri dari 20 item pertanyaan dengan skala likert $1 \mathrm{sd} 4$. Semakin tinggi skor berarti semakin tinggi sifat Machiavellian responden.

b. Independensi $\left(\mathrm{X}_{2}\right)$

Independensi audit merupakan penggunaan cara pandang yang tidak bias dalam pelaksanaan pengujian audit,evaluasi hasil pengujian tersebut dan pelaporan hasil temuan audit (Arens et all 2008:132). Indikator independensi terdiri dua komponen yaitu independensi dalam fakta dan independensi dalam penampilan. Independensi dalam fakta merupakan sikap kejujuran didalam diri akuntan dalam mempertimbangkan fakta-fakta dan adanya pertimbangan objektif, tidak memihak di dalam merumuskan dan menyatakan pendapatnya. Sedangkan independensi dalam penampilan merupakan ketaatan akuntan publik kepada sejumlah aturan yang ditetapkan oleh organisasi profsi guna menampilkan citra independensi dimata masyarakat (Roger W.Barlett 1991:11). Instrumen ini diukur dengan 15 item pertanyaan dengan skala likert 1 sd 4.

c. Orientasi Etis $\left(\mathrm{X}_{3}\right)$

Orientasi etis diartikan sebagai dasar pemikiran untuk menentukan sikap, arah dan sebagainya secara tepat dan benar berkaitan dengan dilemma etis. Orientasi etis diklasifikasikan menjadi dua yaitu orientasi etis idealism dan orientasi etis relativisme. Orientasi etis idealism lebih mengacu pada tindakan individu yang harus sesuai dengan nilai-nilai moral yang berlaku sedangkan orientasi etis relativisme merupakan suatu sikap penolakan terhadap nilai-nilai moral yang absolut, individu masih mempertimbangkan beberaa nilai dari dalam dirinya maupun lingkungan 
Sifat

Machiavellian, Orientasi

Etis...

1028 sekitar. Pengukuran variable ini menggunakan skala likert 1 sd 4 yang dikembangkan oleh Lia Nurfarida (2011) yang terdiri dari 20 item pertanyaan.

d. Equity Sensitivity $\left(\mathrm{X}_{4}\right)$

Equity Sensitivity merupakan suatu persepsi seseorang terhadap keadilan dengan membandingkan antara Inputs dan outcomes yang diperoleh dari orang lain. Husemen (1987) membagi persepsi individu equity dan inequity dalam tiga kategori yaitu benevolents (berpeliraku murah hati, lebih senang memberi), equity sensitivities (individu yang memiliki keseimbangan antara inputs dan outcomes), dan entitleds (individu yang lebih senang menerima dari pada memberi). Istrument yang digunakan adalah Equity Sensitivity Instrumen (ESI) yang dikembangkan oleh Huseman (1985) terdiri dari 10 item pertanyaan dan Equity Preference Questionnaire (EPQ) yang dikembangkan oleh Sauley dan Bedeian (2000) terdiri dari 12 item pertanyaan yang semuanya dikur dengan skala likert $1 \mathrm{sd}$ 4.

e. Budaya Jawa $\left(\mathrm{X}_{5}\right)$

Budaya jawa merupakan budaya yang cenderung mempunyai ciri menjunjung tinggi nilai harmoni. Budaya jawa mengutamakan keseimbangan, keselarasan dan keserasian dalam kehidupan sehari-hari. Budaya jawa menjunjung tinggi kesopanan dan keserhanaan. Pengukuran variable budaya jawa ini menggunakan skala likert 1 sd 4 dengan indikator penghindaran konflik dan rasa menghormati (respect) yang terdiri dari 14 item pertanyaan.

\section{Tehnik Analisis Data}

Penelitian ini menggunakan uji validitas dan reabilitas, uji asumsi klasik, uji hipotesis (uji $\mathrm{F}$ dan uji t) dengan uji regresi dan path analisis.

Model 1 Regresi Sederhana

Untuk membuktikan hipotesis 1 dimana Auditor dengan sifat Machiavellian tinggi akan cenderung berperilaku tidak independen.

$$
\begin{array}{ll}
\text { Keterangan: } \\
\text { MACH } & =\text { Machiavellian } \\
\text { IND } & =\text { Independensi } \\
\beta 0 & =\text { konstanta. } \\
\varepsilon & =\text { error. }
\end{array}
$$$$
\mathrm{MACH}=\beta 0+\beta \mathrm{IND}+\varepsilon \ldots \ldots \ldots \ldots \ldots \ldots \ldots \ldots .(\text { persamaan } 1)
$$

Model 2 untuk membuktikan hipotesis 2, hipotesis 3 , hipotesis 4 , hipotesis 5 , hipotesis 6 $\mathrm{PE}=\beta 0+\beta \mathrm{MACH}+\beta \mathrm{IND}+\beta \mathrm{OE}+\beta \mathrm{ES}+\beta \mathrm{BJ}+\varepsilon$ (persamaan 2)

Keterangan:

$$
\begin{array}{ll}
\mathrm{PE} & =\text { Perilaku Etis } \\
\mathrm{MACH} & =\text { Machiavellian } \\
\mathrm{OE} & =\text { Orientasi Etis } \\
\mathrm{ES} & =\text { Equity Sensitivity } \\
\mathrm{BJ} & =\text { Budaya Jawa }
\end{array}
$$

Model 2 Path Analisis untuk membuktikan tujuan penelitian dimana terdapat hubungan sifat Machiavellian terhadap perilaku etis melalui independensi. 
Adanya hubungan tidak langsung antara sifat Machiavellian denngan perilaku etis auditor berarti bahwa sifat Machiavellian tinggi akan menurunkan independensi auditor. Semakin menurunnya independensi, maka auditor cenderung berperilaku tidak etis.

\section{PEMBAHASAN}

\section{Gambaran Subjek Penelitian}

Subjek penelitian ini adalah auditor yang bekerja pada Kantor Akuntan Publik yang terdapat di Surabaya dengan total sampel yang diperoleh sebanyak 25 auditor dari 50 kuesioner yang dikirimkan. Data responden menunjukkan bahwa sebagian besar yang mengisi kuesioner adalah auditor dengan level junior $(0,66 \%)$ dengan pengalaman rata-rata 2 tahun $(0,72 \%)$, rata-rata $\mathrm{S} 1(0,88 \%)$ dan paling banyak berjenis kelamin laki-laki $(0,66 \%)$. Karena rata-rata yang mengisi adalah level junior maka kebanyakan masih belum memiliki sertifikasi/keahlian (0,22\%).

\section{Hasil Uji Validitas dan Reabilitas}

Berdasarkan hasil uji validitas menyatakan bahwa variable shifat Machiavellian dengan total 20 item terdapat 12 item yang tidak signifikann yaitu pertanyaan ke SM 1 sd SM 7, SM 9, SM 10, SM 16, SM 19, dan SM 20. Hasil uji validitas variable Independen Audit yang terdiri dari 15 item pertanyaan menyatakan bahwa terdapat 5 item yang tidak valid yaitu item pertanyaan ke IA 7, IA 8, IA 10, IA 14 dan IA 15. Hasil uji validitas variabel Orientasi Etis dengan total 20 item pertanyaan terdapat 5 item pertanyaan yang tidak valid yaitu item no OE 1 , OE 4, OE 6, OE 9, dan OE 10. Hasil uji validitas untuk variable Equity Sensityvity menyatakab bahwa dari total 12 item pertanyaan terdapat 5 item yang ditanyatakan tidka valid yaitu item pertanyaan no ES 5, ES 7, ES 9, ES 11 dan ES 12. Hasil uji validitas untuk variable Budaya jawa menyatakan bahwa dari total 14 item hanya 3 item yan gdinyatakan tidak valid yaitu item pertanyaan no BJ 1, BJ 10 dan BJ 11, sedangkan hasil uji validitas untuk variable Perilaku Etis menyatakan bahwa dari 10 item pertanyaan terdapat 5 item yang dinyatakan tidak valid artinya bahwa 50\% pertanyaan tersebut tidak sesuai yaitu item no $\mathrm{PE}$ 1, PE 4, PE 5, PE 6 dan PE 9.

\section{Hasil Uji Determinasi}

Hasil uji deterinasi menunjukkan nilai Adjusted $R$ Square sebesar 0,871 yang berarti variable dependen (Perilaku Etis) dapat dijelaskan oleh variable independen (Sifat Machiavellian, Independensi Audit, Orientasi Etis, Equity Sensitivity, Budaya Jawa) sebesar $87 \%$ sedangkan $13 \%$ dipengaruhi oleah variable lain. Hal ini menunjukkan bahwa variabel independen menjadi pengukuran yang sesuai dalam menilai perilaku etis seorang auditor.

\section{Hasil Uji F}

\begin{tabular}{lllllll}
\multicolumn{2}{l}{ ANOVA $^{\mathrm{a}}$} \\
\hline Model & Sum of Squares & df & Mean Square & F & Sig. \\
\hline 1 & Regression & 570.231 & 5 & 114.046 & 33.270 & $.000^{\mathrm{b}}$ \\
& Residual & 65.129 & 19 & 3.428 & & \\
& Total & 635.360 & 24 & & & \\
\hline
\end{tabular}

a. Dependent Variable: Perilaku Etis

b. Predictors: (Constant), Budaya Jawa, Sifat Machevellian, Independensi Audit, Orientasi Etika, Equity Sensitivity 
Sifat

Machiavellian, Orientasi

Etis...

1030

Tabel 5.2

Uji t Perilaku Etis
Berdasarkan tabel di atas nilai $\mathrm{F}$ hitung menunjukkan angka 2,844 dengan tingkat signifikansi 0,041. Hasil signfikansi tersebut kurang dari 0,05 (0,041< $0,05)$ yang berarti bahwa $\mathrm{H}_{0}$ ditolak. Hal ini dapat disimpulkan bahwa model regresi fit dan layak digunakan untuk pengujian selanjutnya.

\section{Uji Statistik $\mathrm{t}$}

Uji statistik t bertujuan untuk menunjukkan seberapa jauh setiap variabel independen secara individual dalam menjelaskan variasi variabel dependen. Hal tersebut digunakan untuk mengetahui kebenaran pernyataan yang telah dihipotesiskan oleh peneliti. Berpengaruh tidaknya variabel independen terhadap variabel dependen dapat dilihat dari nilai signifikansinya. Apabila nilai signifikansi kurang dari 0,05 maka artinya $\mathrm{H}_{0}$ ditolak sehingga terdapat pengaruh.

\section{Coefficients $^{\mathrm{a}}$}

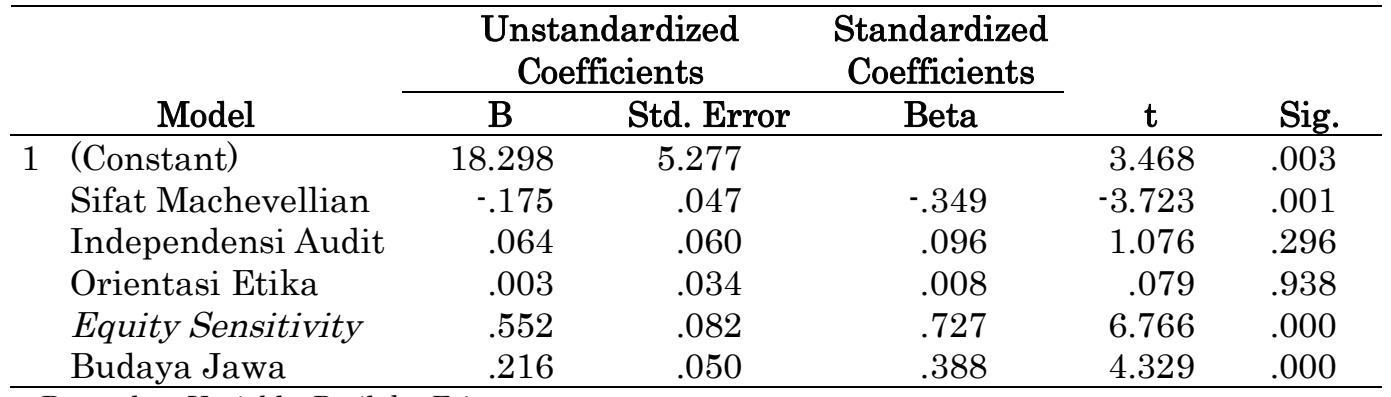

a. Dependent Variable: Perilaku Etis

\section{Pembahasan}

$\mathrm{H}_{1}$ : Auditor dengan sifat Machiavellian tinggi akan cenderung berperilaku tidak independen

Arti sifat Machiavellian tinggi akan cenderung bertindak tidak independen, artinya sifat Machiavellian akan berhubungan negative dengan independensi auditor. Hasil penelitian ini menunjukkan bahwa auditor dengan sifat Machiavellian tinggi akan cenderung tidak independen. Hasil penelitian ini didukung oleh Purnamasari (2006). Dimana individu dengan Machiavellian tinggi cenderung memanfaatkan situasi untuk mendapatkan kepentingan pribadi dan cenderung melalukan manipulasi dan kebohongan meskipun hanya untuk jangka pendek. Hal ini juga mengindikasikan bahwa individu dengan sifat Machiavellian tinggi akan lebih memiliki keinginan untuk tidak taat pada aturan.

$\mathrm{H}_{2}$ : Auditor dengan sifat Machiavellian tinggi akan cenderung berperilaku tidak etis

Seseorang yang memiliki kecenderungan untuk mengontrol dan mempengaruhi ornag lain, orang tersebut dapat dikataka sebagai seorang Machiavellian. McLean (1992) dalam Chrismastuti dan Purnamasari (20014) mengemukakan sterotip Machiavellian sebagai hal yang biasa dapat diterima dalam persepsi profesi bisnis, namun bukan tipe karakter yang sesuai bagi seorang individu dalam berorganisasi. Hasil penelitian ini menunjukkan bahwa auditor dengan sifat $\mathrm{Ma}^{-}$ chiavellian tinggi akan cenderung berperilaku tidak etis, sebaliknya jika kecenderungan sifat Machiavellian rendah maka seseorang akan cenderung untuk berperilaku etis. Hal ini juga didukung oleh Richmond (2001). Sifat Machiavellian yang dimiliki oleh auditor dalam responden ini menunjukkan bahwa peraturan/ aturan-aturan terkait dengan kebijakan-kebijakan perusahaan yang membatasi lingkup audit membuat auditor membatasi hasil auditnya. Auditor dengan sifat Machiavelillan akan memiliki peluang memanipulasi hasil audit untuk kepentingan pribadinya yang mencerminkan rencahnya perilaku etis auditor. Adanya sifat 
Machiavellian dalam diri auditor menyebabkan auditor lebih rentan melakukan perilaku disfungsional atau perilaku tidak etis. Diman individu yang memiliki sifat Machiavellian akan memiliki persepsi bahwa etika dan tanggung jawab social tidaklah penting. Hal ini menunjukkan bahwa sifat Machiavellian yang dimiliki auditor harus dikendalikan agar tidka terjadinya perilaku tidak etis karena profesi sebagai seorang auditor dituntut memiliki tanggung jawab etis pada publik.

$\mathrm{H}_{3}$ : Auditor dengan level independensi yang tinggi akan cenderung berperilaku etis

Independensi merupakan salah satu dari prinsip etika seorang auditor. Independensi audit merupakan penggunaan cara pandang yang tidak bias dalam pelaksanaan pengujian audit,evaluasi hasil pengujian tersebut dan pelaporan hasil temuan audit (Arens et all 2008:132). Hasil penelitian ini tidak embuktikan bahwasannya auditor denga level independensi tinggi akan cenderung berprilaku etis. Hal ini menyatakan bahwa dalam berperilaku etis level individu yang tinggi tidak memiliki pengaruh terhadap sikap seseorang dalam berperilaku.

$\mathrm{H}_{4}$ : Orientasi etis berpengaruh terhadap perilaku etis

Penelitian-penelitian sebelumnya membuktikan bahwa orientasi etis dikendalikan oleh dua karakteristik yaitu idealism dan relativisme. Auditor dengan tingkat idealisme yang tinggi akan menemukan adanya masalah etika dan dalam memutuskan suatu tindakan akan lebih mengarah pada pedoman yang telah ditetapkan sebelumnya sehingga cenderung berperilaku etis. Sebaliknya, auditor dengan tingkat relativisme yang tinggi cenderung menolak aturan moral dan merasa bahwa tindakan moral tergantung pada individu dan situasi sehingga cenderung tidak berperilaku tidak etis. Hasil penelitian ini menyatakan bahwa orientasi etis tidak berpengaruh terhadap perilaku etis. Dimana auditor dalam objek penelitian ini baik yang memiliki sifat idealisme maupun relativisme tidak berpengaruh dengan sikapnya untuk berperilaku etis. Jadi meskipun auditor tersebut memiliki sifat idealism tetapi tetap saja tidak mempengaruhi dalam perilaku etisnya. Penelitian ini juga dudukung oleh Douglas et al (2001) dan menolak penelitiannya Audry (2005) dan Revita Mardani (2014).

$\mathrm{H}_{5}$ : Equity Sensitivity berpengaruh terhadap perilaku etis

Equity Sensitivity merupakan suatu variable personalitas yang menunjukkan reaksi individu ketika merasakan adil atau tidak adil. Individu benevolent digambarkan sebagai individu yang murah hati, yang lebih sering memberi daripada menerima. Kebalikan dengan sifat entitled yang digambarkan dengan sifat individu yang suka menerima daripada memberi dan lebih banyak menuntuk haknya daripada memikirkan apa yang dapat diberikannya, sehingga individu ini cenderung melakukan tindakan tidak etis. Hal tersebut menyatakan bahwa terdapat pengaruh antara equitu sensitivity terhadap perilaku etis.

Hasil penelitian ini terbukti dan mendukung teroi bahwa sifat yang dimiliki individu baik benelovent maupun intitled (Equity Sensitivity) mmemiliki pengaruh terhadap perilaku etisnya. Penelitian ini didukung oleh Putri Nugrahaningsih (2005) yang menyatakan bahwa auditor benevolents cenderung mempunyai perilaku etis. Namun penelitian ini membahtah hasil penelitian Jurica dan Gunardi (2012) yang menyatakan bahwa Equity Sensitivity tidak berpengaruh terhadap perilaku etis.

$\mathrm{H}_{6}$ : Budaya Jawa berpengaruh terhadap perilaku etis

Budaya Jawa memiliki inti bagaimana menjaga harmonisasi sosial. Hubungan sosial masyarakat ini dipengaruhi oleh dua prinsip dasar yaitu penghindaran konflik dan rasa menghormati, dimana prinsip ini akan membentuk pola-pola 
Sifat

Machiavellian, Orientasi

Etis...

1032 berprilaku yang positif apabila diterapkan dengan baik. Inti dari Budaya Jawa adalah bagaimana menjaga harmoni sosial, yang didalamnya meliputi cara hidup yang rukun, yang terintegrasi dalam kesejahteraan kelompok. Hal ini dikarenakan orang jawa lebih memilih untuk bersikap mencari aman dan mendukung orang lain (Audry, 2010). Individu lebih memilih sikap mencari aman dan mendukung orang lain. Auditor yang berasal dari jawa juga akan mempunyai sikap demikian. Hasil penelitian ini menyatakan bahwa terdapat pengaruh Antara budaya jawa terhadap perilaku etis. Dimana budaya itu sendiri akan menciptakan perbedaan yang jelas Antara satu organisasi dengan organisasi yang lain, memberikan identitas suatu organisasi serta memantapkan sistem sosial. Penelitian ini sejalan dengan penelitian Audry (2010) yang membahas tentang pengaruh orientasi etis dan budaya jawa terhadap perilaku etis auditor. Audry menyatakan bahwa budaya jawa berpengaruh positif terhadap perilaku etis auditor, dimana auditor yang berasal dari jawa dan memegang teguh prinsip-prinsip budaya jawa akan cenderung mengembangkan perilaku etis.

\section{KESIMPULAN}

Berdasarkan table 6.1 dibawah ini dapat diambil kesimpulan sebagai berikut:

\begin{tabular}{cll}
\hline Hipotesis & \multicolumn{1}{c}{ Keterangan } & $\begin{array}{l}\text { Hasil } \\
\text { Pengujian }\end{array}$ \\
\hline $\mathrm{H}_{1}$ & $\begin{array}{l}\text { Auditor dengan sifat Machiavellian tinggi akan } \\
\text { cenderung berperilaku tidak independen }\end{array}$ & $\begin{array}{l}\text { Tidak } \\
\text { Terbukti }\end{array}$ \\
$\mathrm{H}_{2}$ & $\begin{array}{l}\text { Auditor dengan sifat Machiavellian tinggi akan } \\
\text { cenderung berperilaku tidak etis }\end{array}$ & Terbukti \\
$\mathrm{H}_{3}$ & $\begin{array}{l}\text { Auditor dengan level independensi yang tinggi akan } \\
\text { cenderung berpengaruh perilaku etis }\end{array}$ & Tidak \\
$\mathrm{H}_{4}$ & $\begin{array}{l}\text { Orientasi etis berpengaruh terhadap perilaku etis } \\
\mathrm{H}_{5}\end{array}$ & $\begin{array}{l}\text { Equity Sensitivity berpengaruh terhadap perilaku etis } \\
\text { Budaya jawa berpengaruh terhadap perilaku etis }\end{array}$ \\
$\mathrm{H}_{6}$ & Tidak & Terbukti \\
& & Terbukti \\
\end{tabular}

\section{SARAN}

1. Sampel dalam penelitian ini masih relative sedikit sehingga untuk penelitian berikutnya dapat menambahkan jumlah auditor.

2. Perlu ditambahkan wawancara untuk memperkuat hasil pembahasan.

3. Perlu mengkaji kembali dengan independensi sebagai variable intervening.

\section{DAFTAR PUSTAKA}

Adji Pratikto. (2012). Pengaruh Budaya Terhadap Kinerja Perekonomian. Buletin Studi Ekonomi. Vol17 No.2:98-115.

Arens, J.K Loebbecke. (2003). Auditing Pendekatan Terpadu. Jakarta. Salemba Empat.

Arianti. (2012). Analisis Perbandingan Perilaku Etis Auditor Dalam Etika Profesi (Study Terhadap Peran Faktor-Faktor Individual: Locus of Control, Job Experience dan Gender.

Audry, leiwakabessy. (2010). Pengaruh Orientasi Etis dan Budaya Jawa terhadap Perilaku Etis Auditor. Jurnal Maksi. Vol 10, No. 1 hal 1-15. 
Duska, RF \& BS Duska. 2006. Accounting Ethics. Blackwell Publishing, Australia.

Husemen, R.C \& Miles. (1987). A New Perspective on Equity Sensitivity Construct. Academy of Management Review. Vo.12:222-234.

Januarti, Indira. (2011). Analisis Pengaruh Pengalaman Auditor, Komitmen Profesional, Orientasi Etis dan Nilai Etika Organisasi Terhadap Persepsi dan Petimbangan Etis (Auditor Badan Pemeriksa Keuangan Indonesia). Simposium Nasional Akuntansi XIV Aceh.

Ludigdo, Unti. (2007). Paradoks Etika Akuntan. Yogyakarta: Pustaka Pelajar.

Purnamasari, Vena. (2006). Sifat Machiavellian dan Pertimbangan Etis: Anteseden Independensi dan Perilaku Etis Auditor.Simposium Nasional Akuntansi 9 Padang.

Putri Nugrahaningsih. (2005). Analisis Perbedaan Perilaku Etis Auditor di Kantor Akuntan Publik dalam Etika Profesi (Studi terhadap Peran Faktor-faktor individual: Locus of Control, Lama Pengalaman Kerja, Gender, dan Equity Sensitivity)" Simposium Nsional Akuntansi VIII Solo: 617-630.

Sujamto. (1992). Refleksi Budaya Jawa. Semarang. Dahara Prize.

Ulum, Ihyaul (2009). Audit Sektor Publik: Suatu Pengantar. Jakarta: PT.Bumi Aksara.

Ustadi,N.H dan Umami, R.D.(2005). Analisis Perbedaan Faktor-faktor Individual Terhadap Persepsi Perilaku Etis Mahasiswa. Jurnal Akuntansi \& Auditing. Vol.1 No.2 hal:162-180

Wilopo, Romanus. 2014. Etika Profesi Akuntan: Kasus-Kasus di Indonesia Edisi Kedua. Peneribit STIE Perbanas Press: Surabaya. 
